\title{
ECCENTRIC AND CONCENTRIC TORQUE OF THE LUMBAR AND HIP EXTENSORS IN FEMALES WITH LOW BACK PAIN
}

\author{
Lamiaa Kottb Elsayyad, Ayman Goda Matar, Amr Almaz Abdel-aziem *, Salam \\ Mohamed Elhafez.
}

Department of Biomechanics, Faculty of Physical Therapy, Cairo University, Giza, Egypt.

\section{ABSTRACT}

Background and objective: The trunk muscles are vital for the maintenance of spinal stability. Little is known regarding the eccentric strength of back and hip extensor in patients with low back pain due to lumbar spondylosis. So, this study was conducted to examine the effect of lumbar spondylosis on the eccentric and concentric peak torque of lumbar and hip extensors muscles.

Materials and Methods: Thirty volunteers participated in the study, 15 patients with lumbar spondylosis and 15 healthy subjects. The isokinetic lumbar and hip extensors' eccentric and concentric peak torque were measured for both groups. The data were collected using the Biodex Isokinetic system 3 at angular velocity of $60 \% / \mathrm{sec}$ for lumbar muscles and $30 \%$ sec for hip muscles.

Results: There was no significant difference in lumbar and hip extensors' eccentric peak torque between both groups ( $p>0.05$ ) respectively. The concentric torque of the lumbar and hip extensors of lumbar spondylosis group was significantly lower than that of the healthy group $(p<0.05)$, the concentric torque of both groups were significantly higher than the eccentric peak torque $(p<0.05)$.

Conclusion: This study displayed that there was no effect of lumbar spondylosis on eccentric torque of lumbar and hip extensors muscles. However, it decreases the concentric torque. So, clinicians must concentrically strengthen the back and hip extensor muscles during designing of rehabilitation program for patients with lumbar spondylosis.

KEY WORDS: Eccentric torque, concentric torque, lumbar spondylosis, hip.

Address for correspondence: Dr. Amr Almaz Abdel-aziem, Assistant Professor of Biomechanics, Faculty of Physical Therapy, Cairo University, 7 Ahmed Elziat Street, Ben Elsaryat, El Dokki, Giza, Egypt.E-mail: amralmaz@yahoo.com; amralmaz74@gmail.com

\section{Access this Article online}

Quick Response code

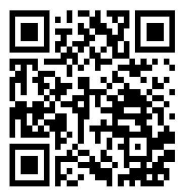

DOI: $10.16965 /$ ijpr.2017.246
International Journal of Physiotherapy and Research

ISSN 2321- 1822

www.ijmhr.org/ijpr.html

Received: 04-10-2017

Peer Review: 05-10-2017

Accepted: 15-11-2017

Revised: None
Published (0): 11-12-2017

Published (P): 11-12-2017

\section{INTRODUCTION}

Lumbar spondylosis and lower back pain (LBP) are considered a major public health issue causing chronic disability of the elderly in most developed countries [1,2]. Chronic LBP due to lumbar spondylosis, is defined as aching low back with or without radiation to lower limbs not less than three months in duration, with confirmed signs of degeneration in lumbar spine on X-Ray [3]. The main feature is pain in lumbar region, often accompanied by restriction in range of motion (ROM) and functional limitation. Risk factors include age, heredity, impact of activity, and occupation. The disabilities related to LBP cause an important socioeconomic burden to society, [4] and it is the most common cause of absence from work [5].

People with recurrent LBP have demonstrated several structural and functional alterations that are situated at multiple peripheral and central levels along the sensorimotor pathway. There 
are divergences in motor output during a variety of lumbar tasks [6-8] and changes in lumbar muscle structure as subsequent to resolution of LBP [9]. In addition, the cortical representation of specific lumbar muscles appeared to be reorganized [10], and changes at the proprioceptive level have been described, during remission of LBP [11].

The trunk muscles are considered important spinal mobilizers and stabilizers $[12,13]$. Depending on the task, cocontraction with the extensors (quadratus lumborum and latissimus dorsi) and the abdominals (rectus abdominis, obliques, and transverse abdominis) ensures stability [13]. The trunk muscle strength had been considered as a possible factor in the etiology of chronic LBP, that has received a great deal of attention in the field of orthopedics and rehabilitation medicine $[14,15]$. Lumbar pain is closely related to lumbar extension muscle strength $[16,17]$. Patients with LBP have decreased cross sectional area and reduced muscle strength of back muscle compared with healthy individuals [18]. Back muscle strength has been considered as one of the most important parameters in patients with chronic LBP and functional disability [19]. There is a relationship between a significant decrease of back muscle strength and chronic LBP or limitation of daily activities [20, 21].

It is reported that the patients with symptomatic lumbar degenerative diseases, the back strength significantly decrease, particularly at lumbar extension positions, and in females and older patients [22]. Moreover, the characteristics of trunk muscle strength in patients with chronic LBP is extremely complicated especially during eccentric contraction mode [17].

The isometric back muscle strength test is one of the most objective measurements of back muscle function $[23,24]$. Many studies involving trunk muscle strength testing have used the isometric strength testing $[23,25,26]$. However, little is known about the eccentric and concentric muscle strength of patients with LBP. The eccentric contraction plays a significant role in the activities of daily living and exercise, it occurs when the external force is greater than the internal force of the muscle, for instance, in deceleration of the body during walking, running, and lifting $[27,28]$. Therefore, this study was conducted to assess the eccentric and concentric peak torque of lumbar and hip extensors muscles in patients with LBP due to lumbar spondylosis.

\section{MATERIALS AND METHODS}

Participants: Thirty female participated in the current study. Fifteen of them were clinically diagnosed with lumbar spondylosis, and fifteen were healthy matching controls. Their demographic characteristics are shown in Tab.1. They were classified as obese grade I (BMI 35$42 \mathrm{~kg} / \mathrm{m}^{2}$ ) according to the World Health Organization (WHO) [29].

Table 1: Demographic characteristics of participants.

\begin{tabular}{|l|c|c|c|}
\hline & $\begin{array}{c}\text { Lumbar } \\
\text { spondylosis } \\
\text { group, } \mathrm{n}=15\end{array}$ & $\begin{array}{c}\text { Healthy } \\
\text { group, } \mathrm{n}=\mathbf{1 5}\end{array}$ & P value \\
\hline Age, years & $50.06 \pm 3.43$ & $48.60 \pm 3.34$ & 0.241 \\
\hline Weight, kg & $91.70 \pm 4.60$ & $90.70 \pm 3.87$ & 0.520 \\
\hline Height, cm & $164.54 \pm 3.02$ & $164.81 \pm 2.61$ & 0.762 \\
\hline BMI, $\mathbf{~ k g / m ^ { 2 }}$ & $33.80 \pm 1.35$ & $33.30 \pm 0.93$ & 0.261 \\
\hline
\end{tabular}

Data are presented as mean \pm standard deviation, *means significant difference $(p<0.05)$.

The inclusion criteria of lumbar spondylosis group were as follows; 1 ) diagnosed with grade Il lumbar spondylosis according to KellgrenLawrence grading scale [1], 2) pain ranged from 4 to 6 (moderate degree according to the numerical pain rating scale) in the last 24 hours prior to isokinetic testing. The pain was felt in the region between T12 and the gluteal fold. Their pain should have lasted for more than three months with the primary complaint being in the back not the leg, 3) their functional disability score ranged from $21 \%$ to $40 \%$ indicating a moderate degree of disability as assessed using Oswestry disability questionnaire [30]. The healthy group had no musculoskeletal, or neurologic problems. A written consent form was signed by each participant. The study was performed in accordance with the Declaration of Helsinki and approved by the local institutional review board.

Procedure: The eccentric and concentric peak torque had been measured by using the Biodex system 3 multi-joint testing and rehabilitation system (Biodex medical system, Shirley, NY, USA). The numerical pain rating scale had been 
used to evaluate pain intensity during the last 24 hours prior to isokinetic testing. The patient was asked to assign a number, from zero to ten according to the severity of her pain [31]. The oswestry disability questionnaire (ODQ) is a functional scale that assesses the impact of LBP on daily activities [30].

Regarding the back extensor peak torque the participant sat on the adjustable trunk testing chair. The sitting position allows greater trunk ROM both in flexion and extension and hence it was the preferred testing position [17,32, 33]. Both thighs were then stabilized by two straps and the feet held in position with the feet off the ground. While the participant was sited erect, the head was stabilized neutrally on an adjustable head seat. The posterior force application padded roller bar was placed on the posterior trunk just distal to the spine of the scapula. The axis of the actuator arm was aligned with the level of anterior superior iliac spine. This axis position was used as it is easy to be located, especially in obese subjects, which provide consistency throughout the study [32]. The lumbar extension torque had been measured through $20^{\circ}$ extension and $40^{\circ}$ flexion.

For the hip extensor torque the hip attachment was attached to the dynamometer shaft and the thigh pad was placed two inches proximal to the popliteal fossa. The participant stood in a comfortable position. The axis of the machine was aligned with greater trochanter. Standing position was selected as it is more functional. Additionally it is easier as the gravitational factor in any other position is quite considerable and it can cause some difficulty [32]. The participant performed the test through 30 o flexion and $10^{\circ}$ extension.

The participant performed a series of three sub-maximal repetitions of the isokinetic test to be familiar with the device. Then, the participant was asked to do five consecutive maximal repetitions by using the eccentric-concentric mode for lumbar extensors at angular velocity $60 \% / \mathrm{sec}$, and the hip extensor assessed at angular velocity $30 \% \mathrm{sec}$, this velocity was recommended to examine the hip joint musculature [34]. A gravity correction was performed for each participant.
Statistical analysis: All statistical measures were performed through the statistical package for social studies (SPSS) version 20 for windows. The eccentric and concentric peak torque ( $\mathrm{Nm})$ of the trunk and hip extensors were compared. Prior to final analysis, data were screened for normality and homogeneity of variance assumptions. This exploration was done as a pre-requisite for parametric calculations of the analysis of difference. Independent t-tests were conducted to determine if there are any significant differences in the mean values of age, weight, height, or BMI between both groups. The alpha level was adjusted to 0.05 .

The dependent variables (peak torque of trunk and hip extensors) were tested with one independent variable (tested group) which had two levels (healthy controls and patients with lumbar spondylosis). Accordingly, one way multivariate analysis of variance MANOVA was used to compare the dependent variables between the lumbar spondylosis group and healthy group.

\section{RESULTS}

There was no significant difference between lumbar sponylosis and healthy group in relation to their age, weight, height, and BMI ( $p=0.241$, $0.520,0.762,0.261$ ) respectively. There was no significant difference between the eccentric peak torque of the lumbar extensor of both groups $(p=0.156)$. However, the concentric peak torque of the lumbar extensor of lumbar sponylosis group was significantly lower than that of the healthy group $(p=0.011)$. The concentric peak torque was significantly higher than the eccentric peak torque in both groups $(p=0.032,0.028)$ respectively, as illustrated in Table 2.

Regarding the hip extensor torque; there were no significant differences between the healthy and lumbar sponylosis group in eccentric torque of right and left sides $(p=0.190,0.100)$ respectively. The concentric peak torque of hip extensors of lumbar sponylosis group was significantly lower than that of the healthy group in both sides $(p=0.001)$. The concentric peak torque was significantly higher than the eccentric torque in both groups $(p=0.029,0.041)$ respectively (Table 2 ). 


\begin{tabular}{|c|c|c|c|c|c|}
\hline \multirow{3}{*}{$\begin{array}{l}\text { Table 2: The eccentric and } \\
\text { concentric peak torque } \\
\text { values ( } \mathrm{Nm} \text { ) of the lumbar } \\
\text { and hip extensors }\end{array}$} & & & $\begin{array}{l}\text { Lumbar } \\
\text { sponylosis } \\
\text { group, } n=15\end{array}$ & $\begin{array}{l}\text { Healthy group, } \\
\quad \mathrm{n}=15\end{array}$ & $P$ value \\
\hline & \multirow{2}{*}{ Lumbar extensor torque } & Eccentric & $66.57 \pm 4.27$ & $64.32 \pm 4.18$ & 0.156 \\
\hline & & Concentric & $112.01 \pm 14.62$ & $52.66 \pm 7.02$ & $* 0.011$ \\
\hline \multirow{4}{*}{$\begin{array}{l}\text { Data are presented as mean } \\
\pm \text { standard deviation, } * \text { means } \\
\text { significant difference }(p< \\
0.05)\end{array}$} & \multirow{4}{*}{ Hip extensor torque } & Right eccentric & $32.51 \pm 1.46$ & $31.09 \pm 2.89$ & 0.190 \\
\hline & & Right concentric & $84.66 \pm 8.63$ & $46.97 \pm 7.04$ & $* 0.001$ \\
\hline & & Left eccentric & $31.64 \pm 1.65$ & $30.78 \pm 1.71$ & 0.100 \\
\hline & & Left concentric & $81.92 \pm 7.01$ & $45.30 \pm 6.93$ & $* 0.001$ \\
\hline
\end{tabular}

\section{DISCUSSION}

The current study was conducted to examine the effect of LBP due to lumbar sponylosis on the eccentric and concentric peak torque of lumbar and hip extensors muscles. The results revealed that there was no difference between the eccentric torque of both groups that may be explained by the difficulty encountered by participants during performing eccentric contraction. This difficulty may be due to lack of experience in this type of contraction that is supported by the findings of the study that proved that the neuromuscular activity is suppressed during maximal eccentric muscle contraction in untrained subjects due to reduced levels of central activation and reduced efferent motor neuron [35]. Moreover, the discharge rate of motor units is less during eccentric contractions across different loading conditions [36].

The concentric peak torque of the lumbar and hip extensors of lumbar sponylosis group was lower than the healthy group that is supported by the findings of the previous study that proved that the muscle endurance is low for people with LBP than individuals without low back pain [37]. Moreover, fatigue can affect the ability of people with low back pain to respond to the demands of an unexpected load. Fatigue after repetitive loading also leads to a loss of control and precision, which may predispose an individual to developing LBP [38].

In addition, LBP reduces the muscle strength and cross sectional area of the back muscles [18]. Previous studies $[22,39,40]$ assessed the back muscle strength in patients with chronic LBP showed significant decreases of isometric strength in patients lumbar degenerative diseases. However, the decrease of muscle strength was much bigger at lumbar extension positions than at flexion positions. The muscle strength of patients with severe LBP were even lower at extension angular positions $\left(0-48^{\circ}\right)$.

The results sug-gest that isometric strength at extension positions could be more associated with back pain of patients with lumbar degenerative diseases than those at flexion positions. The concentric peak torque of the lumbar and hip extensor were higher than the eccentric contraction in both groups that was against the findings of Tis et al. [41] who found significant increase in the eccentric activities of hip and lumbar flexors and extensors when compared with the concentric activities. Moreover, they mentioned that it is difficult to ascertain whether this finding is limited to female runners, or if this observation may be generalized to a sedentary population.

These results contradict with most of the previous studies that compared between the eccentric and concentric muscle contraction; During isokinetic assessment of the elbow flexors, it is observed that the eccentric torque was about $80 \%$ higher than concentric torque [42]. At angular velocity $90 / \mathrm{sec}$, similar results were found, that 22 and $60 \%$ greater force values during eccentric muscle actions if compared to concentric contractions. Similarly, when free weights are used, eccentric actions are still showing greater force values than concentric [43]. Although the reasons that may explain these discrepancies are still not well understood, higher maximal forces developed during eccentric contractions seems to be related with muscle viscoelastic properties associated with motor unit activation. However, interpretation of these results should be done with caution since variables like exercise type and participants characteristics may influence the outcomes [44]. 
The eccentric contraction was lower than the concentric in healthy subjects and patients with chronic LBP [17] that is support the lower value of eccentric torque of the present study. However, this result was not coincident with findings of the study that evaluated the concentric and eccentric torque of the hip musculature in individuals with and without patellofemoral pain. It proved that the eccentric torque was always higher than concentric activities in both groups except for hip abductor which showed higher values during the concentric activities [45].

Indeed, neural adaptations in eccentric contraction seem to be different compared with concentric contraction. There are several characteristic of eccentric muscle contraction when compared with concentric contraction that included broader and faster cortical activity as movements are being executed, inversed motor unit activation pattern, increased cross-education effect, faster neural adaptations secondary to resistance training, attenuated muscle sympathetic nerve activity, reduced electromyographic amplitude at similar force levels, and greater electromyography signal prior to the onset of movement [46].As, there is not specific explanation to this findings, it is recommend to conduct further studies that examine the eccentric torque of lumbar and hip extensors in different conditions and populations. The present study had several potential limitations. Including only the patients with LBP due to lumbar spondylosis without consideration of other causes of LBP. In addition, the present study was limited to only female participants. So, in-terpretation of the results could be limited to this specific population. The only measured isokinetic parameter during conduction of this study was the peak torque without consideration of other parameters like as; power, fatigue and work were not considered. Lastly, the sample size was small, that is due the restricted inclusion and exclusion criteria. So, it is recommended to conducted this study on a larger sample for generalization of the results. Future study that examined the effect of fatigue on the eccentric and concentric torque of lumbar and hip extensors is needed.

\section{CONCLUSION}

In patients with LBP due to lumbar spondylosis there is a decrease in the concentric torque of the lumbar and hip extensors compared with the healthy group, without difference between the eccentric torque of both groups. Moreover, the lumbar and hip extensors concentric torque was higher than the eccentric torque of both groups. These results could aid in understanding of the contractile properties of the extensor muscles of the back and hip joint in subjects with LBP. So, clinicians must concentrically strengthen the back and hip extensor muscles during designing of rehabilitation program for patients with lumbar spondylosis.

\section{ACKNOWLEDGEMENTS}

The authors would like to thank the participants involved in the study. The authors gratefully acknowledge the support of Mrs. Noha Khairy Fouad, the teacher of English for language editing and revising the manuscript.

\section{Conflicts of interest: None}

\section{REFERENCES}

[1]. Muraki S, Oka H, Akune T, Mabuchi A, En-Yo Y, Yoshida $M$, et al. Prevalence of radiographic lumbar spondylosis and its association with lower back pain in the elderly of population-based cohorts: the ROAD study. Ann Rheum Dis. 2008;68:1401-1406.

[2]. Muraki S, Akune T, Oka H, En-yo Y, Yoshida M, Saika $A$, et al. Impact of knee and lower back pain on health-related quality of life in Japanese women: the Research on Osteoarthritis Against Disability (ROAD). Modern Rheum. 2010;20:444-451.

[3]. Middleton K. Fish DE. Lumbar spondylosis: clinical presentation and treatment approaches. Curr Rev Musculoskelet Med. 2009; 2:94-104.

[4]. Miller JK. The Meckenzie Approach. Clin Orthop. 1992;279:8-20.

[5]. Albright J, Allman R, Bonfiglio RP, Conill A, Dobkin B, Guccione AA, Hasson SM, Russo R, Shekelle P, Susman JL. et al. Philadelphia panel evidence-based clinical practice guidelines on selected rehabilitation interventions for neck pain. Phys Ther. 2001;81:1701-1717.

[6]. D'Hooge R, Cagnie B, Crombez G, Vanderstraeten G, Achten $E$, Danneels L. Lumbar muscle dysfunction in remission from unilateral non-specific low back pain-evaluation with muscle functional MRI. Clin J Pain. 2013; 29: 187-194.

[7]. Jones SL, Henry SM, Raasch CC, Hitt JR, Bunn JY. Individuals with non-specific low back pain use a trunk stiffening strategy to maintain upright posture. J Electromyogr Kinesiol. 2012; 22: 13-20.

[8]. Macdonald DA, Moseley GL, Hodges PW. People with recurrent low back pain respond differently to trunk loading despite remission from symptoms. Spine 2010;35: 818-824. 
[9]. D’Hooge R, Cagnie B, Crombez G, Vanderstraeten G, Dolphens M, Danneels L. Increased intramuscular fatty infiltration without differences in lumbar muscle cross-sectional area during remission of unilateral recurrent low back pain. Man Ther. 2012;17:584-588.

[10]. Tsao H, Danneels LA, Hodges PW. ISSLS prize winner: Smudging the motor brain in young adults with recurrent low back pain. Spine 2011;36:1721-1727.

[11].Brumagne S, Cordo P, Lysens R, Verschueren S, Swinnen $S$. The role of paraspinal muscle spindles in lumbosacral position sense in individuals with and without low back pain. Spine 2000;25: 989994.

[12]. McGill SM, Grenier S, Kavcic N, Cholewicki J. Coordination of muscle activity to assure stability of the lumbar spine. J Electromyogr Kinesiol. 2003;13:353-359.

[13]. Gardner-Morse MG, Stokes IA. The effects of abdominal muscle coactivation on lumbar spine stability. Spine (Phila Pa 1976) 1998;23:86-91.

[14]. Hageman PA, Gillaspie DM, Hill LD. Effects of speed and limb dominance on eccentric and concentric isokinetic testing of the knee. J Orthop Sports Phys Ther. 1988;10:59-65.

[15]. Shirado O, Ito T, Kaneda K, Strax TE. Lumbar trunk muscle endurance in patients with chronic low-back pain. The reliability and safety of a new method. Proceedings of the 21 st Annual Meeting of International Society for the Study of the Lumbar Spine; 1994 June 15-19; Seattle. 1994.

[16]. Mayer T, Gatchel R, Betancur J, Bovasso E. Trunk muscle endurance measurement; isometric contrasted to isokinetic testing in Control subjects. Spine 1995, 20(8): 920-927.

[17]. Shirado O, Ito T, Kaneda K, Strax TE. Concentric and eccentric strength of trunk muscles: Influence of test postures on strength and characteristics of patients with chronic low-back pain. 1995; Arch Phys Med Rehabil. 1995; 76: 604-611.

[18]. Demoulin C, Crielaard JM, Vanderthommen M. Spinal muscle evaluation in healthy individuals and low-back-pain patients: a literature review. Joint Bone Spine 2007;74:9-13.

[19]. Hirsch G, Beach G, Cooke C, Menard M, Locke S. Relationship between performance on lumbar dynamometry and Waddell score in a population with low-back pain. Spine (Phila Pa 1976) 1991;16:10391043.

[20]. Imagama S, Matsuyama Y, Hasegawa Y, et al. Back muscle strength and spinal mobility are predictors of quality of life in middle-aged and elderly males. Eur Spine J. 2011;20:954-61.

[21]. Sertpoyraz F, Eyigor S, Karapolat H, Capaci K, Kirazli Y. Comparison of isokinetic exercise versus standard exercise training in patients with chronic low back pain: a randomized controlled study. Clin Rehabil. 2009;23:238-247.

[22]. Park WH, Lee CS, Kang KC, Seo YG. Characteristics of back muscle strength in patients with scheduled for lumbar fusion surgery due to symptomatic lum bar degenerative diseases. Asian Spine Journal. 2014;8(5):659-666.

[23]. Azghani MR, Farahmand F, Meghdari A, Vossoughi $G$, Parnianpour M. Design and evaluation of a novel triaxial isometric trunk muscle strength measurement system. Proc Inst Mech Eng H 2009;223:755766.

[24]. Keller TS, Szpalski M, Gunzburg R, Spratt KF. Assessment of trunk function in single and multi-level spinal stenosis: a prospective clinical trial. Clin Biomech (Bristol, Avon) 2003;18:173-181.

[25]. Kim YS, Park J, Hsu J, Cho KK, Kim YH, Shim JK. Effects of training frequency on lumbar extension strength in patients recovering from lumbar dyscectomy. J Rehabil Med 2010;42(9):839-845.

[26]. Ostelo RW, Costa LO, Maher CG, de Vet HC, van Tulder MW. Rehabilitation after lumbar disc surgery: an update Cochrane review. Spine (Phila Pa 1976) 2009;34:1839-1848.

[27]. Joynt RL, Findley TW, Boda W, Daum Me. Therapeutic exercise. In: DeLisa JA, Gans BM, editors. Rehabilitation medicine: principles and practice. Philadelphia: Lippincott, 1993:526-554.

[28]. Ellenbecker TS, Davies GJ, Rowinski MJ. Concentric versus eccentric isokinetic strengthening of the rotator cuff. Am J Sports Med. 1988;16:64-69.

[29]. Kearns K, Dee A, Fitzgerald AP, Doherty E, Perry IJ. Chronic disease burden associated with overweight and obesity in Ireland: the effects of a small BMI reduction at population level. BMC Public Health 2014;14:143. doi: 10.1186/1471-2458-14-143.

[30]. Fairbank J, Pynsent P. The Oswestry disability index. Spine 2000;25(22):2940-2952.

[31]. Richardson C, Jull G, Hodges P, Hides J. Therapeutic exercise for spinal segmental stabilization in low back pain: scientific basis and clinical approach. Churchill Livingstone, 1999.

[32]. Dvir Z. Isokinetics: Muscle Testing, Interpretation and Clinical Applications. Churchill Livingstone, 1995; pp. 92, 93, 96, 147 and 153.

[33]. Yahia A, Ghroubi S, Kharrat O, Jribi S, Elleuch M, Elleuch, M. A study of isokinetic trunk and knee muscle strength in patients with chronic sciatica. Ann phys rehabil med. 2010;53(4):239-244.

[34]. Eng J, Kim C, Maclntyre D. Reliability of lower extremity strength measures in persons with chronic stroke. Arch phys med rehabil. 2002;83(3):322-328.

[35]. Aagaard P. The use of eccentric strength training to enhance maximal muscle strength, explosive force (RDF) and muscular power-consequences for athletic performance. Open Sports Sci J. 2010;3:52-55.

[36]. Duchateau J, Baudry S. Insights into the neural control of eccentric contractions. J Appl Physiol. 2014;116(11):1418-1425.

[37]. Hultman G, Nordin M, Saraste H, Ohlsen H. Body composition, endurance, strength, cross-sectional area, and density of MM erector spinae in men with and without low back pain. J Spinal Disord. 1993;6:114-123.

[38]. Parnianpour M, Nordin M, Kahanovitz N, Frankel V. The triaxial coupling of torque generation of trunk 
muscles during isometric exertions and the effect of fatiguing isoinertial movements on the motor output and movement patterns. Spine 1988;13:982992.

[39]. Lee KW, Hwang JH, Bang HJ. Isometric evaluation of the lumbar extensors in chronic low back pain. J Korean Acad Rehabil Med. 1997;21:1-7.

[40]. Scheuer R, Friedrich M. Reliability of isometric strength measurements in trunk and neck region: patients with chronic neck pain compared with painfree persons. Arch Phys Med Rehabil. 2010;91:18781883.

[41]. Tis L, Perrin, D, David SP, Weltman A. Isokinetic strength of the trunk and hip musculature in female runners. Isokinet Exer Sci. 1991;1(1):22-25.

[42]. Rodgers KL, Berger RA. Motor-unit involvement and tension during maximum, voluntary concentric, eccentric, and isometric contractions of the elbow flexors. Med Sci Sports1974;6:253-259.
[43]. Hortobagyi T, Katch FI. Eccentric and concentric torque-velocity relationships during arm flexion and extension. Influence of strength level. Eur J Appl Physiol Occup Physiol. 1990; 60:395-401.

[44]. Hollander DB, Kraemer RR, Kilpatrick MW, Ramadan ZG, Reeves GV, Francois M, et al. Maximal eccentric and concentric strength discrepancies between young men and women for dynamic resistance exercise. J Strength Cond Res. 2007;21:34-40.

[45]. Boling MC, Padua DA, Alexander Creighton R. Con centric and eccentric torque of the hip musculature in individuals with and without patellofemoral pain. J Athl Train. 2009;44(1):7-13.

[46]. Roig M, O’Brien K, Kirk G, Murray R, McKinnon P, Shadgan $B$, et al. The effects of eccentric versus concentric resistance training on muscle strength and mass in healthy adults: a systematic review with meta-analysis. Br J Sports Med. 2009;43(8):556-568.

How to cite this article:

Lamiaa Kottb Elsayyad, Ayman Goda Matar, Amr Almaz Abdel-aziem, Salam Mohamed Elhafez. ECCENTRIC AND CONCENTRIC TORQUE OF THE LUMBAR AND HIP EXTENSORS IN FEMALES WITH LOW BACK PAIN. Int J Physiother Res 2017;5(6):2545-2551. DOI: 10.16965/ijpr.2017.246 